geometry and algebra, which include a welcome account of the problem of the locus ad quatuor lineas, from which, it is believed, co-ordinate geometry was born.

The book is copiously illustrated; and the author has had the happy idea of including brief biographies of all the minor personalities mentioned in the text. Printing and binding are excellent.

L. ROTH

\section{CRYSTALLOGRAPHICAL STRUCTURE REPORTS FOR 1949}

Structure Reports for 1949

Vol. 12. General Editor : A. J. C. Wilson. (Published for the International Union of Crystallography.) $\mathrm{Pp}$. viii +478. (Utrecht : A. Oosthoek's Uitgevers Mij., 1952.) 45 Dutch florins.

$7 \mathrm{HE}$ format of Vol. 11-as the prototype of the new series of "Structure Reports" published by the International Union of Crystallography-excited almost as much interest at the time of its publication as the structural data it contained, for with it there reappeared a valuable series of reference works upon which one may confidently rely.

With the appearance of Vol. 12, one can turn directly to the contents, since it was prepared by the same editors more-or-less concurrently with Vol. 11 and is strictly isomorphous with it, being strongly bound, well printed, adequately illustrated and extremely comprehensive; the arrangement within individual reports is, as before, name, formula, papers reported, unit cell, space group, atomic positions and parameters, interatomic and intermolecular distances, material, discussion, details of analysis and references. Happily the editors have been entirely successful in providing this wealth of detail without that sacrifice of clarity which makes the extraction of information from some reference books almost a kind of parlour game.

It is a striking indication of the potentialities of structural crystallography that the work reported in this volume represents the output of but a single year - a prodigious quantity even after allowance has been made for the publication of work carried on during the War, such as the investigation of penicillin and of many of the compounds of the trans-uranium elements. Current trends are everywhere discernible; for example, in the organic section, there are reports on the increasingly accurate determinations of the structure of aromatic hydrocarbons now available for comparison with quantum mechanical calculations, while in the inorganic section are some of the firstfruits of the neutron diffraction experiments, such as the structure of $\mathrm{UH}_{3}-\mathrm{a}_{4}$ most unpromising substance for a crystallographer equipped only with X-rays. There are also reports of structure determination from single-crystal electron diffraction patterns.

One striking thing is the steady increase of symmetry from the frequently monoclinic or even triclinic crystals of organic compounds through the mainly orthogonal lattices of the inorganic section to the predominantly cubic structures of the metals section. This high symmetry is a valuable asset when one realizes how much of the work on alloys is done with powders. Occasional references to as yet unindexed patterns of high complexity remind us that a really satisfactory generalized solution of powder patterns of any symmetry is still required, in spite of some recent advances. As regards technique, however, one wonders whether the statement on p. 231, that "Absences, observed on Laue and oscillation photographs, show the above space group" $\left(P 2_{1} 2_{1} 2_{1}\right)$, indicates an unusually ingenious experimenter, or merely a tired abstractor.

The fullness of these structure reports makes the volumes particularly useful for rapid surveys of special topics in which one is currently interestedsuch as carbon-sulphur bond-lengths, or the frequency of polymorphism among organic erystals. Since useful ideas can be quickly substantiated in this way, and unprofitable speculations as rapidly deflated, such books are a constant challenge to review the data from some novel point of view, and thus a powerful stimulus to us all to avail ourselves of the rich diversity of experimental material now available as a starting-point for new adventures into the unknown.

H. J. GRENVILIE-WELLS

\section{STRUCTURAL LINGUISTICS}

\section{Methods in Structural Linguistics}

By Zellig S. Harris. Pp. $x v+384$. (Chicago : University of Chicago Press; London: Cambridge University Press, 1951.) 56s. 6d. net.

HE basic concept of structural linguistics is substitutability, and the nature of the subject may be explained by the two following examples. First, in the English word kingcup, the two [k]-sounds are well known to be different (I write $k_{1} i n g k_{2} u p$ ) ; if, now, the philologist, interchanging them, says $k_{2}$ ing $k_{1} u p$ to a native English speaker, he is told that the interchange is immaterial ; if, however, he substitutes the initial sound of man for $k_{1}$, producing mingk $k_{2} u p$, he is told that the interchange is not immaterial (for a Ming cup is not a kingcup). By this procedure the philologist has learnt that there is an essential difference between the distinction $k_{1} / k_{2}$ and the distinction $k_{1} / m$; he therefore makes one 'phoneme' [k], materializing in at least two forms $k_{1}$ and $k_{2}$, and another, different phoneme [m]. Secondly, the informant will allow the substitution of from for to and will not allow that of dog for to in the phoneme-block Come to London; in this way the philologist learns that to and from are 'morphemes' of the same kind and that $d o g$ is a different kind of morpheme from to.

Prof. Z. S. Harris's long and complicated book is essentially devoted to the problems indicated by the above two examples. He describes how the phonemes and morphemes of a language may be set up by the sole aid of a native informant (as an example of the first procedure, he sets up the phonemes of Swahili). His account of the concepts and methods is entirely lucid; regrettably, the book lacks an index of authors cited-were such an index made, many philologists might feel that it contained an undue proportion of American names.

Structural linguistics appears, rather refreshingly, to have little theory underlying it; it is a purely practical discipline, and it therefore stands or falls solely according to whether it does or does not accomplish what it purports to that is, to extract the phonemes and morphemes of a hitherto unstudied language. With regard to phonemes, the 'cross-word puzzle' method which Mr. J. Josephs and I advocate 1 is undoubtedly greatly superior to the structural- 